nonreversal conditions, the tactual mode of presentation (i.e., the T-T and V-T conditions) interfered with the acquisition of the shift solution in comparison to Ss who were presented this problem visually.

Finally, in the reversal condition form cues were easier to discriminate than size cues, whereas in the nonreversal condition, there were no differences in ease of learning as a function of kind of stimulus cue.

\section{DISCUSSION}

The findings that the reversal shift was learned more rapidly than the nonreversal shift is in agreement with the mediation theory of discrimination (e.g., Kendler \& Kendler, 1962). However, had younger Ss (i.e., preschoolers) been used in the investigation, it would be expected, according to the mediation theory, that the nonreversal shift would have been easier to master than the reversal shift.

It is of some interest to note that normally sighted Ss were able to effectively cope with the initial concept task under tactual as well as under visual conditions. Accordingly, it might be expected that both the reversal and nonreversal shift solutions would have been acquired as rapidly under tactual conditions as under visual conditions. This was not the case, for the results showed that a differential effect was produced under tactual conditions-namely, an apparently facilitating effect in a reversal shift but an interfering effect in a nonreversal shift. The question arises as to what aspects of a tactual presentation contributes to this effect. One possibility suggested by Piaget $\&$ Inhelder (1956) is that the tactual discrimination of shapes requires an active searching operation if such discrimination is to occur. In contrast, such an intensive exploration in the visual modality might occur only when relatively complex stimuli are presented. Therefore, it is suggested that the reversal shift was facilitated under tactual conditions(i.e., the T-T and the V-T groups) because of the greater perceptual demands in comparison to a visual presentation. That is, for tactual recognition and discrimination to occur, the $S$ must be more attentive to the available cues before a choice is made. Perhaps this contributes to his learning the task requirements to a degree not possible under a visual presentation. However, there may be conditions under which a tactual presentation may enhance the difficulty level of a task to a degree which far exceeds the information processing capacity of the individual. This might be the case for a nonreversal shift where, in comparison to the reversal shift, the $S$ must not only acquire a new instrumental response but also a new mediational or cueing response (Kendler \& Kendler, 1962). Under these conditions a visual rather than a tactual
Table 1

Means and Standard Deviations of Total Errors to Criteria on Problem 2

\begin{tabular}{lrrrrrrr}
\hline & \multicolumn{3}{c}{ Reversal Shift } & & \multicolumn{2}{c}{ Nonreversal Shift } \\
\cline { 2 - 3 } & $\mathrm{N}$ & $\mathrm{M}$ & $\mathrm{SD}$ & & $\mathrm{N}$ & $\mathrm{M}$ & SD \\
\hline Modality of Presentation & & & & & & & \\
Visual-Visual & 10 & 11.13 & 6.86 & & 10 & 12.72 & 8.25 \\
Visual-Tactual & 10 & 9.92 & 7.90 & 10 & 25.84 & 10.46 \\
Tactual-Visual & 10 & 13.54 & 7.46 & 10 & 10.71 & 7.81 \\
Tactual-Tactual & 10 & 7.61 & 4.36 & 10 & 14.73 & 8.14 \\
\hline
\end{tabular}

presentation might provide the optimal perceptual condition to acquire the appropriate cue-response associations.

It might be argued that the findings in part reflect cues provided by a cross-modal shift (e.g., from a visual to tactual presentation). That is, a change in modality might signify to the $S$ a new task, thereby facilitating the solution of the shift problem. Certain considerations argue against this position. First, the fact that rapid reversal learning was noted in the T-T group, where no modality shift occurred, as well as in the V-T group, argues against this possibility. Second, if learning cues were associated with a cross-modal shift, one might also expect that a nonreversal solution would be facilitated in the visual-tactual condition. Such was not the case as both the T-T and V.T groups exhibited relatively slow nonreversal learning.

In conclusion, it would be important to determine whether the findings extend beyond the particular dimension stimuli used in the present investigation. Thus, it would be useful to increase the cognitive demands involved in discriminating stimuli visually and tactually. For example, it might be that the visual presentation of more complex stimuli might enhance attention
(Cantor \& Cantor, 1964) and hence facilitate reversal learning under visual conditions. Furthermore, many studies have identified such variables as overlearning (e.g., Eimas, 1966) and the verbalization of cues (e.g., Kendler \& Kendler, 1961) as factors facilitating reversal and nonreversal learning. It would thus be of some interest to examine how these variables interact with modality of presentation in influencing concept learning.

REFERENCES

BLANK, M., ALTMAN, L. D., \& BRIDGES, W.H. Crossmodal transfer of form discrimination in preschool children. Psychonomic Science, 1968, 10,51-52.

CANTOR, J. H., \& CANTOR, G. N. Observing behavior in children as a function of stimulus novelty. Child Development, 1964, 35, 119-128.

EIMAS, P. D. Effects of overtraining and age on intradimensional and extradimensional shifts in children. Joumal of Experimental Child Psychology, 1966, 3, 348-355.

KENDLER, H. H., \& KENDLER, T. S. Effects of verbalization on reversal shifts in children. Science, 1961, 134, 1619-1620.

KENDLER, H. H., \& KENDLER, T. S. Vertica and horizontal processes in problem solving. Psychological Review, 1962, 69, 1-16.

PIAGET, J., \& INHELDER, B. The child's conception of space. London: Routledge \& Kegan Paul, 1956.

\title{
Speech rate as a measure of imitative performance
}

A. J. FINCH, JR., K. A. LATTAL, ${ }^{1}$ and H.
C. RICKARD, University of Alabama,
University, Ala. 35486

Imitative performance was assessed by two different tasks. In the speech-rate phase, 20 males and 20 females repeated numbers after a female model speaking at either one number per $2 \mathrm{sec}$ (2.0-sec group) or one number per $0.5 \mathrm{sec}$ (0.5-sec group). During the content phase, these same Ss said words intermittently with a taped female model who emitted an increasing frequency of animal words across trial blocks. Both phases yielded significant imitation, but a significant correlation between the two measures of modeling failed to emerge. 
Kanfer \& Marston (1963) have introduced an experimental paradigm which permits the exploration of variables related to verbal matching performance including direct and vicarious reinforcement (Kanfer \& Marston, 1963; Marston \& Kanfer, 1963; Marston, 1964, 1966), status of the model (Rickard \& Lattal, 1967; Rickard \& Joubert, 1968), and task requirements (Kanfer \& Marston, 1963; Marston, 1966). The S hears a series of tape-recorded words spoken by a model $(M)$; the $M$ emits an increasing frequency of words from a critical response class, e.g., animal words. Ss tend to match the behavior of $M$ by emitting an increasing frequency of critical words across successive blocks of trials.

It is of interest to consider the possibility of speech rate as a measure of imitative or matching behavior. Webb (1967) varied two speech-rate measures in an automated standardized interview. Although he was primarily interested in standardized interview behavior, it is possible to interpret Webb's findings in a modeling framework. The primary purpose of the present experiment was to determine the usefulness of speech rate as a potential measure of imitation within the Kanfer and Marston paradigm. Additionally, a possible relationship between the imitation of speech rate and the matching of verbal content was examined.

\section{SUBJECTS}

Twenty females and 20 males from introductory psychology classes served as Ss. Three other Ss were excluded from the experiment because of apparatus failure or operation of the equipment by means other than speech, e.g., excessive coughing, moving chair, etc.

\section{APPARATUS}

Subjects were seated about 12 in. from a panel in an $8 \times 7 \mathrm{ft}$ experimental room. A small stimulus light was mounted in the lower middle portion of the panel, and a microphone about 3 in. below the signal light. Ss wore earphones which were part of an intercommunication system with the adjacent room from which $S$ 's speech was automatically timed. Speech rate was recorded by a Grason-Stadler Model E7300A voice-operated relay. A timer was activated by S's first response and continued to run until $S$ had not spoken for $3 \mathrm{sec}$. Time was measured in $.1 \mathrm{sec}$. The readings on the voice-operated relay were: gain, 3.5; attack time, 5.0; and release time, 5.0.

\section{PROCEDURE}

In the speech-rate design, a tape was recorded in which a female $M$ repeated sets of five one-digit numbers at the rate of one number per $2 \sec$ ( $2.0-\mathrm{sec}$ group). A second tape was recorded by the same female $M$ in which the same sets of five numbers were repeated at the rate of one number per $0.5 \sec (0.5-\sec$ group). Each $S$ responded to a list of 40 sets of five numbers selected from a table of random numbers. The second phase of the study was modified from a vacarious responding procedure employed by Smith \& Marston (1965). The same female $M$ said 50 words at 3-sec intervals. In succeeding blocks of 10 words, the critical response class, in this instance names of animals, occurred with a respective frequency of $0,2,4,6$, and 8 .

The experimental design for the speech-rate phase was a two-factor design combining the speech-rate groups $(2.0 \mathrm{sec}$ and $0.5 \mathrm{sec}$ ) and the sex of the $S$. In each of the four groups, 10 Ss were placed: female, $2.0 \mathrm{sec}$; female, $0.5 \mathrm{sec}$; male, $2.0 \mathrm{sec}$; and male, $0.5 \mathrm{sec}$. The design in the content phase of the experiment was a mixed design with one between-S (sex) and one within-S (blocks of trials) variable (Myers, 1966). Twenty Ss were placed in each of these two groups.

All Ss were read the following instructions: "The experiment in which you are about to participate is composed of two studies. After the first one you will be given a short break."

The next two sets of instruction (and associated task, as indicated above) were presented in a counterbalanced order. The speech-rate instructions were: "Your task in this experiment will be to listen to a tape recording of numbers through earphones. After every five numbers, your signal light will come on. This is your signal to repeat the five numbers which you have just heard on the tape. Remember, repeat only the five digits you have just heard and not all the previous ones." The verbal content instructions were: "This is a study to see how different people use words. I am asking you to wear earphones so that you may hear what is said on the tape recorder in the next room. A word will be spoken and then a light will blink which is your signal to say a word. Give the first word you think of. Just one word. Do you have any questions?"

Between the first and second part of the experiment there was a brief pause during which $E$ set the tape in the proper position for the next portion of the experiment and then read the final set of instructions.

\section{RESULTS AND DISCUSSION}

The last 10 blocks of trials were analyzed in the speech-rate design. An analysis of variance clearly indicates that speech rate of the $S$ was influenced by speech rate of the $M$ $[F(1,76)=16.08, p<.001]$. Modeling of speech rate was unaffected by sex of the $S$, and there was no interaction between the main experimental variables. Analysis of variance for the word-content measure yielded a significant modeling effect $[F(4,152)=30.62, p<.001]$. A significant sex-of-S effect was not found, nor was there a significant interaction between main variables as previously observed (Rickard \& Joubert, 1968). To determine the relation between modeling as measured by the content procedure with that of the speech-rate method, Ss were ranked in terms of modeling from most to least on the two measures and a Spearman rank order correlation calculated. The expected relationship between modeling rate of speech and modeling of content failed to emerge $(\mathrm{Rho}=.016, \mathrm{p}>.10)$.

The results indicate that speech rate is a sensitive measure of modeling. The lack of a significant correlation between speech-rate modeling and content modeling was unexpected. Bandura (1965) states, however, that persons are quite discriminative in the types of behaviors they select to reproduce, and he predicts modest intercorrelations among different classes of matching responses. The present study offers ad hoc support for such a prediction.

\section{REFERENCES}

BANDURA, A. Social-learning theory of identificatory processes. In D. A. Goslin and D. C. Glass (Eds.), Handbook of socialization theory and research. Chicago: Rand McNally, 1968.

KANFER, F. H., \& MARSTON, A. R. Human reinforcement: Vicarious and direct. Journal of Experimental Psychology, 1963, 65, 292-296.

MARSTON, A. R. Variables in extinction following acquisition with vicarious reinforcement. Journal of Experimental Psychology, 1964, 68, 312-315.

MARSTON, A. R. Determinants of the effects of vicarious reinforcement. Journal of Experimental Psychology, 1966, 71, 550-558.

MARSTON, A. R., \& KANFER, F. H. Group size and number of vicarious reinforcements in verbal learning. Journal of Experimental Psychology, 1963, 65, 593-596.

MEYER, J. L. Fundamentals of experimental design. Boston: Allyn \& Bacon, 1966.

RICKARD, H. C., \& JOUBERT, C. E. Subject-model sexual status and observer performance. Psychonomic Science, 1968, 10, 407-408.

RICKARD, H. C., \& LATTAI, K. A. Model similarity and observer learning. Psychological Reports, 1967, 21, 501-506.

SMITH, F. J., \& MARSTON, A. R. The effects of inter- and intra-response class differences upon learning via vicarious reinforcement. Journal of Verbal Learning \& Verbal Behavior, 1965, 4, 360-364.

WEBB, J. T. An analysis of two speech role measures in an automated standardized interview. Unpublished doctoral dissertation, University of Alabama, 1967. NOTE

1. Now at Medical Research Laboratories, Edgewood Arsenal, Md. 21010. 